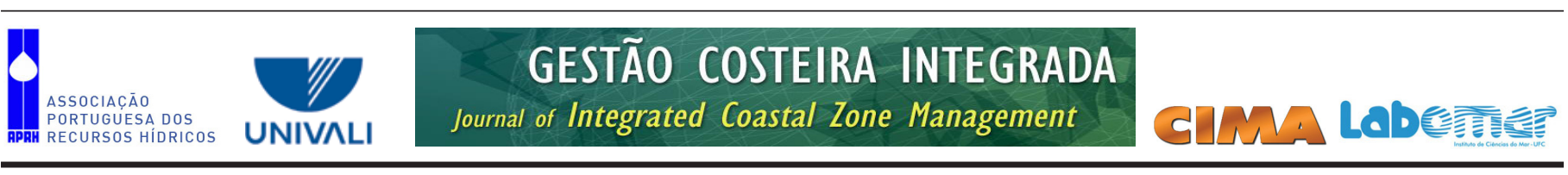

http://www.aprh.pt/rgci/pdf/rgci-446_Fidalga.pdf | DOI:10.5894/rgci446

\title{
Estudo das perceções da comunidade da Palmeira (Ilha do Sal, Cabo Verde) sobre a Sustentabilidade das Pescas *
}

\author{
Palmeira community residents' perceptions (Ilha do Sal island, Cape Verde) on \\ environmentally Sustainable Fishing
}

\author{
Alécia Brígida Pires Fidalga ${ }^{\circledR, 1}$, Sónia Seixas ${ }^{2}$, Ulisses M Azeiteiro ${ }^{3}$
}

\section{RESUMO}

A pesca teve sempre grande importância socioeconómica para as comunidades costeiras de Cabo Verde, oferecendo meios de subsistência e, devido à vocaçáo marítima do povo Cabo-verdiano, possibilidades de emprego. O peixe aparece como componente importante na alimentação da população e, por ser fonte de proteína e um animal de baixo custo para a população, requer que a sua exploraçáo seja feita em moldes sustentáveis, perpetuando no tempo a disponibilidade desse recurso para toda a sociedade.

Este trabalho apresenta o estudo das perceçóes dos pescadores sobre a sustentabilidade da exploração dos recursos haliêuticos pesqueiros e a pesca artesanal dominante na ilha. A pesca é uma das principais atividades económicas da zona costeira da Ilha do Sal, além de ser uma importante atividade de subsistência para as três comunidades haliêuticas da ilha.

Com o objetivo de discutir caminhos sustentáveis para a atividade, reflete-se sobre a sustentabilidade da pesca artesanal na comunidade da Palmeira, Ilha do Sal, Cabo Verde. Numa comunidade como a Palmeira, onde a pesca é tipicamente artesanal, encontramos diversos elementos que garantem a sustentabilidade da atividade.

Conhecer e desenvolver novos mecanismos que visam educar e criar políticas sustentáveis para a atividade e gestão dos recursos é importante para a nova conjuntura em que se vive. A educação e a organização dos pescadores, bem como a descentralização e a gestão participativa dos recursos pesqueiros, são condiçóes fundamentais para a sustentabilidade da pesca.

Este trabalho tenta responder à escassez de estudos sobre as comunidades piscatórias em Cabo Verde de modo a favorecer o conhecimento ambiental que potenciará a criação de estratégias-chave para a sustentabilidade, a análise dos projetos criados até à data e a respetiva implementaçáo, permitindo a identificação das causas do insucesso total ou parcial, bem como a identificação das causas para o fraco envolvimento da comunidade piscatória na implementação dos projetos.

Palavras-chave: pesca artesanal; sustentabilidade; recursos haliêuticos; diagnóstico socio-ambiental.

\section{@- Corresponding author}

1 - Escola Secundária Olavo Moniz, Bairro Novo, Ilha do Sal, Cabo Verde / Universidade Aberta. Departamento de Ciências e Tecnologia. Mestrado em Cidadania Ambiental e Participação. E-mail: brigidafidalga@hotmail.com

2 - Universidade Aberta. Departamento de Ciências e Tecnologia. Palácio Ceia. Rua da Escola Politécnica, 141 - 147. 1269-001 Lisboa, Portugal e IMAR, CMA, University of Coimbra, Rua da Matemática, no 49, 3004-517 Coimbra, Portugal.E-mail: sonia.seixas@uab.pt

3 - Universidade Aberta. Departamento de Ciências e Tecnologia. Palácio Ceia. Rua da Escola Politécnica, 141 - 147. 1269-001 Lisboa, Portugal/ Centro de Ecologia Funcional, Universidade de Coimbra.e-mail: ulisses@uab.pt 


\section{ABSTRACT}

Fishery has always been of great social economic importance for the coastal communities of Cape Verde, offering means of subsistence and employment opportunities due to their maritime vocation. Fish is an important food component for the population. Since fishery is a source of low-cost animal protein, its exploration must be sustainable in order to be permanently available for the community.

This paper presents a study on the perception of fishermen on the sustainable exploitation of fishery resources in a symbiosis with the dominant artesanal fishing practiced on the island.

Fishing is one of the main economic activities of the coastal zone of Sal island, besides being an important subsistence activity for the three fishing communities of the island. Aiming to discuss ways for sustainable activity, we will reflect on the sustainability of the traditional fishing in the community of Palmeira, Sal Island, Cape Verde. In a community like Palmeira, where fishing is typically artesanal, we find many elements that ensure the sustainability of the activity, such as the predominant use of renewable natural resources and the diversity of species caught.

in Sal Inland knowing and developing new mechanisms to educate, create sustainable policies for the activity and resource management are important to the environment. Education and organization of fishermen, as well as decentralization and participatory management of fishery resources, are fundamental to the sustainability of fisheries.

This work tries to answer the scarcity of studies on fishing communities in order to promote environmental knowledge that will enhance the creation of key strategies for sustainability, the analysis of projects created to date and the respective implementation, allowing the identification of the causes of the total or partial failure, as well as the identification of the causes for the poor involvement of the fishing community in the implementation of projects.

Keywords: handmade fishing; sustainability; stocks; socio-environmental diagnosis.

\section{INTRODUÇÁO}

Cabo Verde é um arquipélago, situado no oceano Atlântico, separado por cerca de $500 \mathrm{Km}$ do continente africano. Formado por dez ilhas e alguns ilhéus, o arquipélago de $4.033 \mathrm{~km} 2$ situa-se entre a latitude $14^{\circ} 23^{\prime} \mathrm{N}$ e $17^{\circ} 12^{\prime} \mathrm{N}$ e a longitude $22^{\circ} 40^{\prime} \mathrm{O}$ e $25^{\circ} 22^{\prime} \mathrm{O}$.

Sendo um país insular, Cabo Verde pertence à região da Macaronésia juntamente com os arquipélagos dos Açores, Canárias e Madeira, onde a pesca desempenha um papel fundamental, já que contribui para diminuir a dependência da importação de alimentos, garante o retorno de divisas, que alavancam outros setores, promovendo o desenvolvimento económico. A pesca é ainda a principal fonte de proteína animal consumida no arquipélago e atividade geradora de emprego.

A atividade pesqueira constitui, hoje, um dos principais desafios ao processo de desenvolvimento regional, sobretudo em relaçáo à necessidade de conciliar a conservação dos sistemas naturais e a utilização racional dos recursos provenientes destes, favorecendo a adoçáo de um modelo de desenvolvimento que associe os aspetos sociais, ecológicos e económicos.

Cabo Verde é um país muito rico em diversidade de peixes, conseguindo reunir espécies características das zonas temperadas da África e das Caraíbas, que dificilmente se encontram noutros locais sendo, no entanto, a sua abundância relativamente baixa (ver Almeida et al., 2004).

$\mathrm{O}$ arquipélago possui uma extensa zona económica exclusiva (ZEE), de aproximadamente $750.000 \mathrm{~km} 2$, com uma produção pesqueira próxima de 10.000 toneladas anuais. Cabo Verde é um arquipélago onde se vive basicamente da agricultura, pesca, pecuária, atividades industriais e o turismo.

A pesca contribui para a criação de emprego, redução do êxodo rural, equilíbrio da balança de pagamentos e segurança alimentar. Para além disto, os recursos marinhos têm grandes possibilidades de gerar riqueza através da sua revalorização, designadamente com a promoção do ecoturismo.
Como afirma Morin (2011), a cultura enquanto conhecimento e o conhecimento enquanto cultura são a dialética que movimenta, interage e dá sentido à vida e às práticas de pesca que, por sua vez, se refletem em saberes que permitem aos pescadores se relacionarem com o meio onde estấo inseridos de maneira íntima, proporcionando a criatividade e a sabedoria.

O conhecimento da variaçáo dos ciclos ambientais e da bioecologia dos recursos é imprescindível para o pescador e para a pescaria. Segundo Diegues (1999), permite que desenvolvam práticas apropriadas de manejo, a fim de assegurar os seus meios de subsistência. É nesta visão que este trabalho pretende explorar o conceito de sustentabilidade junto dos pescadores da comunidade da Palmeira.

$\mathrm{Na}$ comunidade, mais de 126 pescadores vivem exclusivamente da pesca, sendo 52 botes para a pesca artesanal e 2 embarcações de pesca industrial e semi-industrial. 32\% da comunidade vive da pesca e $25 \%$ da pesca artesanal, que é uma atividade limitada quando comparada com a pesca industrial, mas preponderante para a alimentação e renda das famílias (INDP, 2012).

Desta forma, o presente trabalho teve como objetivo principal a análise dos aspetos socioeconómicos, a atividade pesqueira e a forma de comercializaçáo do pescado, a vida dos pescadores e a perceção ambiental sobre a sustentabilidade da pesca artesanal com a finalidade de reunir subsídios que permitam que a exploração pesqueira seja feita em moldes sustentáveis, perpetuando a disponibilidade desse recurso para toda a sociedade.

\section{MATERIAL E MÉTODOS}

\section{1. Área de estudo}

O porto de pesca de Palmeira e a sua comunidade piscatória ficam localizados a uma distância de $3 \mathrm{~km}$ (quilómetros) do centro, a oeste dos Espargos. A comunidade conta com uma população residente estimada de 1420 indivíduos (INDP, 2010). Estão registados na capitania marítima da ilha 1.090 
(mil e noventa) pescadores e 789 (setecentas e oitenta e nove) embarcaçóes, das quais 422 (quatrocentas e vinte e duas) com motor (INDP, 2010). A comunidade piscatória em estudo vive da faina da pesca e de outras atividades complementares. A localização ilha do Sal é evidenciada na figura 1.
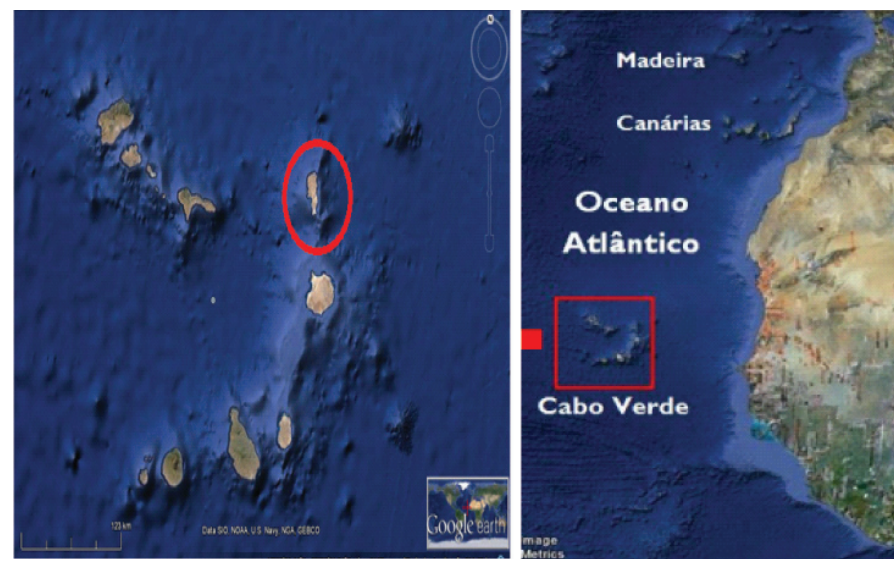

Figura 1. Mapa (C) (Google Earth) do Arquipélago de Cabo Verde ilustrando a ilha do Sal

Figure 1. Map (C) (Google Earth) of the Cape Verde Archipelago illustrating the island of Sal.

\subsection{Metodologia}

Além do levantamento bibliográfico, para a coleta das informaçóes foram elaboradas entrevistas semiestruturadas e inquéritos, contendo perguntas fechadas relacionadas às características socioeconómicas, perfil dos pescadores, dinâmica da atividade pesqueira, registro de campo, além do registro in loco de informaçóes pertinentes às características ambientais.

O tipo de pesquisa classifica-se como descritiva e analítica, ou seja, a pesquisa realizada, através de entrevistas, coleta de dados em campo e observação. Segundo Deslandes (2004), a metodologia não apenas contempla o momento exploratório de campo (escolha do espaço da pesquisa, escolha do grupo de pesquisa, estabelecimento dos critérios de amostragem e construção de estratégias para entrada em campo), como também determina os instrumentos e procedimentos a serem utilizados na análise dos dados.

Dos 468 pescadores das comunidades piscatórias da ilha do Sal, 126 pertencem à comunidade do Porto da Palmeira. Para este estudo, teve-se o cuidado de inquirir um pescador por cada embarcação, num total de 27 pescadores. Os dados secundários foram obtidos junto das autoridades/entidades reguladoras da atividade pesqueira da Palmeira. A localização da localidade em estudo está evidenciada na figura 2.

Otrabalho que aqui seapresenta baseia-se nos fundamentos da pesquisa-ação com metodologia de pesquisa, onde se visou estabelecer uma estrutura coletiva, participativa ativa para a captação de informaçóes (Thiollent, 1992).

As entrevistas foram realizadas de forma fragmentada e aleatória ao longo do período de amostragem: alguns pescadores foram entrevistados no momento em que

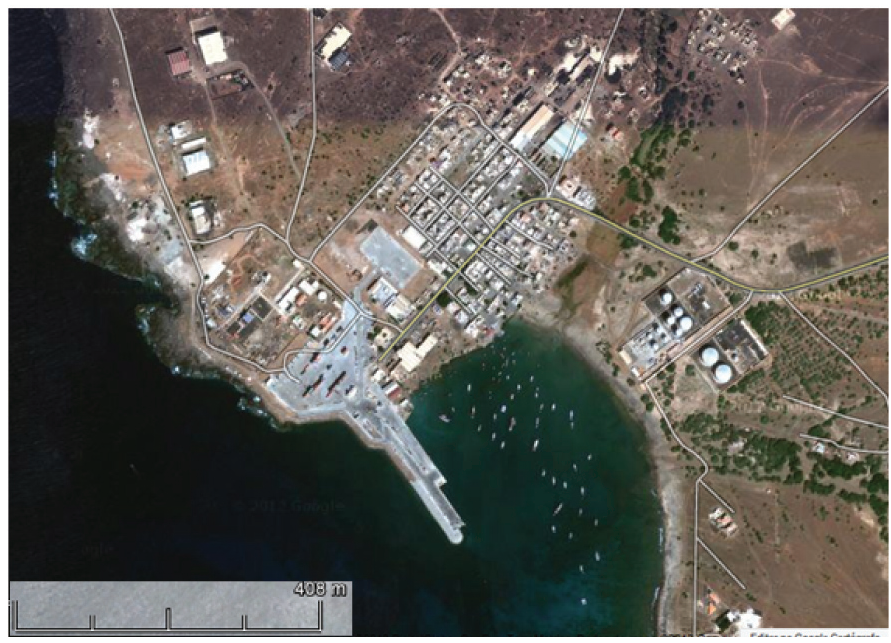

Figura 2. Localização da comunidade em estudo. Fonte: Google Earth Figure 2. Location of the comunity under study. Source: Google Earth

retornavam da atividade pesqueira, quando indicavam outros pescadores para futuras entrevistas (método da bola-de-neve) (Goodman, 1961). Outras entrevistas foram realizadas nos locais de desembarque, nas embarcaçóes e até mesmo nas residências dos pescadores. Nos questionários, procurouse obter informaçóes referentes às características das embarcaçóes utilizadas, número de tripulantes, instrumentos de navegação e material de segurança, assim como os tipos de artes de pesca, as espécies capturadas por arte de pesca, as áreas de pesca e a conservação do pescado a bordo.

Os dados obtidos foram analisados e organizados em Excel, utilizando o programa SPSS (IBM SPSS, versão 15) para análise e apresentação gráfica. A análise de dados foi feita através das informações relativas às temáticas abordadas nos questionários e, de acordo com as respostas, foi possível apresentar resultados especificando os respetivos percentuais, utilizando estatística descritiva.

\section{RESULTADOS}

No inquérito aplicado, procurou-se caracterizar o perfil dos entrevistados. $100 \%$ dos inquiridos na amostra são do sexo masculino. Destes, a maioria, 19 indivíduos, tem mais de 40 anos de idade, representando $70 \%$ dos inquiridos (Figura 3). Ao cruzar a variável idade e anos de atividade constatamos que 18 indivíduos (66,6\%) têm mais de 20 anos a dedicar-se à pesca.

Quanto à escolaridade observou-se que cerca de $74 \%$ são analfabetos. Ao fazer o cruzamento das variáveis idade e nível de escolaridade verificou-se que o pescador inquirido acima dos 40 anos de idade náo tem o $1^{\circ}$ grau completo (Figura 4).

Em termos demográficos, grande parte dos pescadores inquiridos têm entre 3 a 6 filhos, enquanto 22\% náo têm filhos. Ao cruzarmos a variável idade com o número de filhos, na faixa etária dos 41 - 50 anos 44,4\% da prole é maior, seguidos dos 20 - 30 anos e $51-60$ anos, ambos com 18,5\%. Quanto ao nível de ensino dos filhos, evidenciou uma rutura com a realidade dos pais/pescadores, uma vez 
que cerca de $63 \%$ dos filhos destes já se encontram a estudar. Destes, cerca de $33 \%$ encontram-se a frequentar o ensino secundário e os restantes estão no ensino de nível superior.

A maior parte dos pescadores entrevistados, 54,5\%, nasceu noutras ilhas, particularmente em Santo Antâo, 44,5\%, e $11 \%$ em São Vicente, enquanto o restante é natural da Ilha do Sal (figura 5). Tal deve-se ao facto de, nos últimos anos, a Ilha do Sal ter atraído milhares de migrantes de outras ilhas devido à sua dinâmica económica, principalmente na oferta de novas oportunidades de trabalho geradas pelo turismo.

Quanto à origem das embarcaçôes, 63\% são da Ilha do Sal, $25,9 \%$ de Santo Antáo e 7,4\% da Brava. Também de modo a permitir uma análise mais concisa do ano de construção foi adotada uma escala, sendo que $22,2 \%$ dos barcos foram

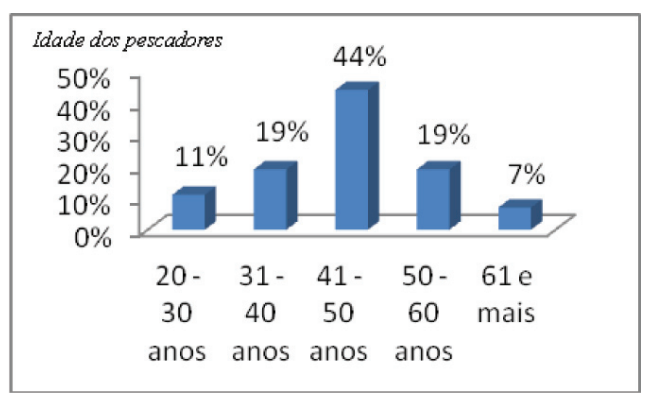

Figura 3. Idade dos pescadores inquiridos.

Figure 3. Age of interviewed fishermen.

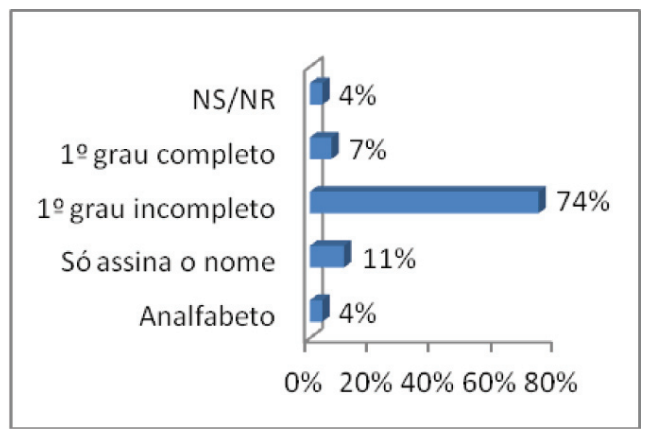

Figura 4. Nível de escolaridade dos entrevistados. Figure 4. Level of education of respondents.

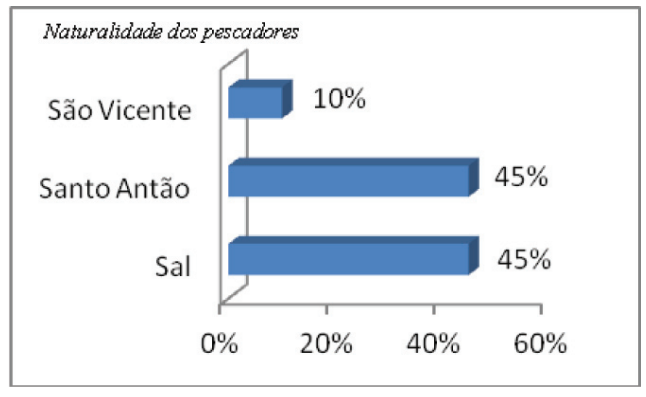

Figura 5. Naturalidade dos pescadores entrevistados. Figure 5. Place of Birth of the fishermen. construídos entre 1990 - 1996, 29,6\% entre 2000 - 2006 e 37\% de 2007 a 2012, porém 3,7\% dos inquiridos não souberam responder sobre a origem das embarcaçóes. Quanto à forma de aquisição das embarcações, 40,7\% dos pescadores mandou construir a embarcação, $37 \%$ comprou com dinheiros próprios a embarcação já construída, 18,5\% adquiriu embarcações através de projetos subsidiados e 3,7\% não responderam.

A maior parte das embarcaçóes utilizadas na comunidade é de madeira e fibra (55,6\%), 25,9\% exclusivamente de madeira, $14,8 \%$ de fibra de vidro e $3,7 \%$ de chapa.

A frota analisada durante o estudo, na comunidade da Palmeira, apresenta 2 tipos básicos de embarcaçóes, sendo a esmagadora maioria constituída por botes, sendo o mais pequeno com 4,5 metros de comprimento e 1,90 metros de largura, com capacidade para 700 quilos. $\mathrm{O}$ maior barco de pesca tem 37 metros de comprimento, 12 metros de largura, e tem capacidade para 40 toneladas (Figura 6).

Das embarcaçôes observadas, $74,1 \%$ utilizam motor de popa e $22,2 \%$ motor de rabeta. O combustível utilizado maioritariamente é a gasolina $(92,6 \%$ dos pescadores inquiridos) e 7,4\% utiliza o gasóleo.

Referente ao número de tripulantes das embarcaçóes verifica-se que este varia. Constata-se que as embarcaçóes com redes de emalhar possuem entre 13 e 14 pessoas; as
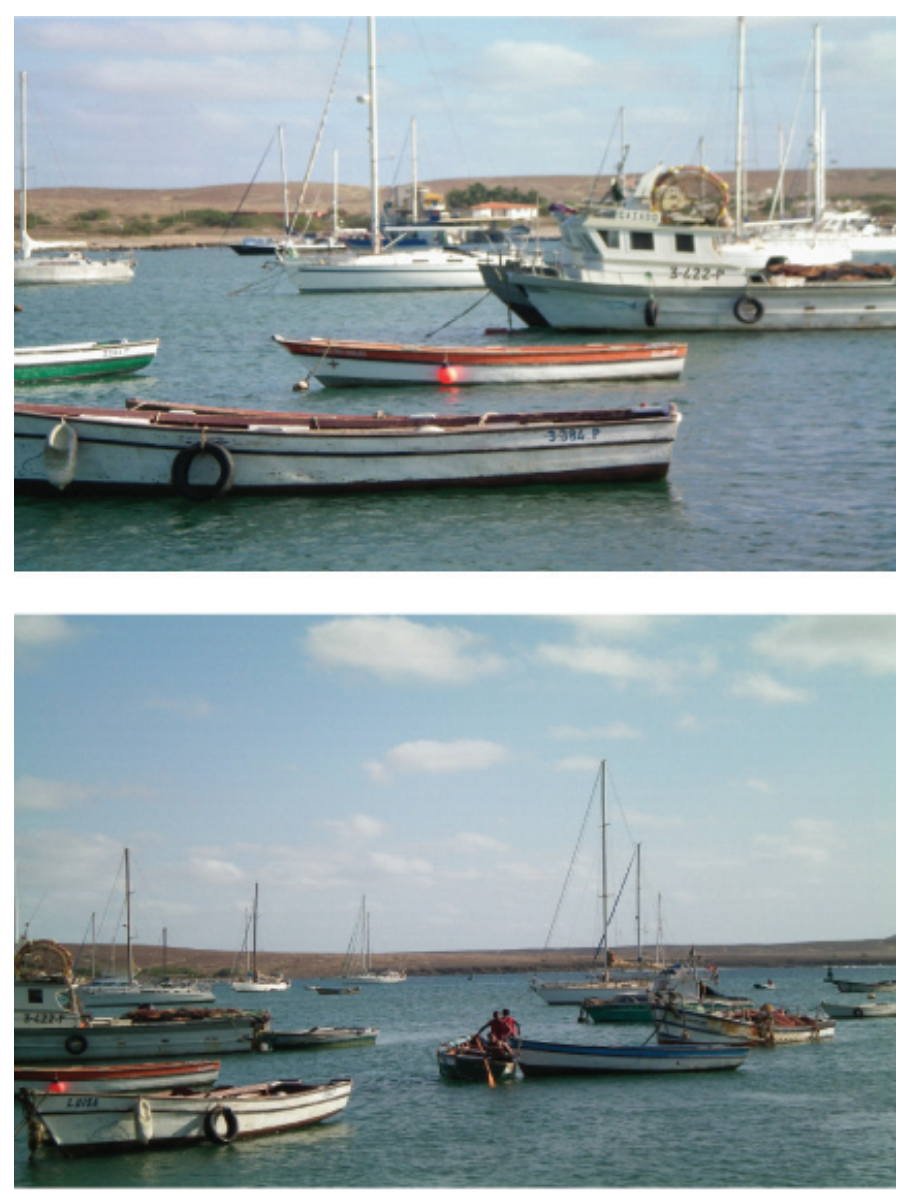

Figuras 6. Tipos de Embarcaçóes encontradas na área de estudo. Figures 6. Boats typology in the study area. 
com rede de arrasto 3 a 9 pessoas; as de linha de máo 2 a 9 pessoas; e, por último, a embarcação com rede de cerco com 9 tripulantes.

Das vinte e sete embarcaçóes analisadas na comunidade da Palmeira $78 \%$ não possuem qualquer tipo de instrumento de navegação; em $22 \%$ embarcaçóes constata-se a presença de um ou outro instrumento, nomeadamente a bússola uma vez que esta é considerada pelos pescadores o principal instrumento de navegação e orientação na pesca.

Relativamente aos equipamentos de segurança observouse que $59 \%$ das embarcaçôes não possuem tais equipamentos contra $41 \%$ que afirmam possuir alguns, tais como coletes de segurança, extintor, boia, bote salva-vida, etc. À semelhança de outras comunidades piscatórias estudadas pelo INDP (vários números), na Palmeira os barcos de pesca não possuem infraestruturas, nem instrumentos que auxiliam a navegação (Figura 7).

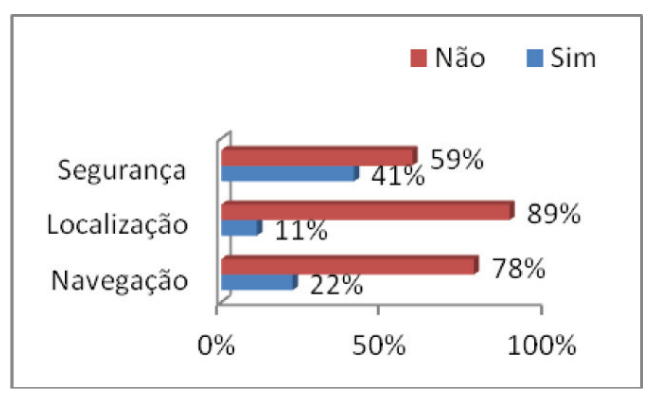

Figura 7. Percentagem das embarcaçóes com instrumentos de segurança.

Figure 7. Percentage of vessels with security tools.

Os dados da pesquisa revelaram que a arte de pesca mais utilizada na localidade da Palmeira é a linha de mão, de acordo com $77,8 \%$ dos pescadores inquiridos, seguido da rede de arrasto, rede de emalhar e rede de cerco, este último com apenas 3,7\% (Figura 8). Estes tipos de redes possuem características idênticas, no entanto apresentam variaçóes de tamanho, malha, procedimento e espécie-alvo de captura.

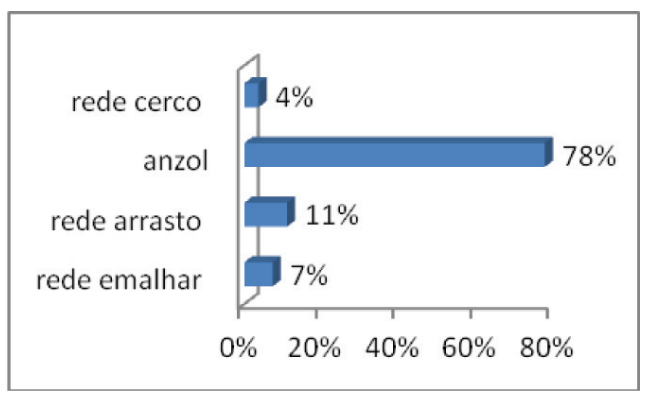

Figura 8. Arte de pescas utilizadas pelos pescadores locais.

Figure 8. Art of fishing used by local fishermen.
Na comunidade da Palmeira, cerca de $44 \%$ dos pescadores inquiridos afirmam que pescam no alto mar, 33\% disseram que concentram suas pescarias a quilómetros da costa e apenas $19 \%$ atuam noutras ilhas, sendo que $4 \%$ não responderam. Já questionados sobre o tempo de pesca, 74,1\% dos inquiridos indicam a duração de apenas algumas horas, 18,5\% duram menos de 5 dias e $7,4 \%$ náo responderam.

A capacidade de armazenamento de gelo para as embarcaçóes inquiridas varia entre 30 quilos a 30 toneladas. Destas, a capacidade de pescado para tal quantidade de gelo é de 60 quilos por 40 toneladas de pescado. Tal se deve ao facto de as embarcaçóes variarem de comprimento, largura e capacidade. A frota pesqueira local, na sua maioria, náo utiliza qualquer sistema de conservaçáo do pescado, sendo que $59 \%$ dos pescadores inquiridos afirmam ainda que, embora as embarcaçóes tenham capacidade para colocar gelo, estes deixam o peixe sem o gelo, justificando que o tempo de pesca (em horas) não deteriora o produto. $33 \%$ dos inquiridos utiliza a caixa de "isópor" (esferovite) com gelo e apenas 7,4\% têm urnas com gelo para fazer a conservação.

O financiamento da pescaria é feito muitas das vezes pelo próprio proprietário, como afirmam $85 \%$ dos inquiridos e apenas $15 \%$ pelo armador. A partilha da pescaria em $48 \%$ dos botes é distribuída em partes iguais (proprietário, barco, motor e pescadores). Outras vezes faz-se a distribuição a meias, sendo que apenas $3,7 \%$ dos pescadores inquiridos são assalariados.

Quanto ao desembarque do pescado, é feito no Porto da Palmeira (100\% dos pescadores), o que influencia diretamente a distribuição e compra do produto, sendo $96 \%$ destinado ao consumo local e apenas $4 \%$ enviado para a cidade da Praia - capital do país.

Dos inquiridos, a maioria, 66,7\% pertencem à Associação de Pescadores da Palmeira - a única associação desta natureza na comunidade - enquanto $33,3 \%$ náo pertencem a nenhuma associação ou cooperativa.

Quanto ao rendimento do pescado obtido ao longo de uma semana verificou-se que se apresenta de forma variada por cada pescador, em virtude do método usado para pesca e também pelo tempo despendido na atividade. $\mathrm{O}$ rendimento mensal dos pescadores locais que dependem exclusivamente da pesca como atividade profissional ronda os 30 a 400 Euros.

A atividade piscatória é tida como uma atividade dura, com rendimentos reduzidos. Assim, questionados sobre o modo de vida na pesca, $67 \%$ acha que é razoável enquanto $33 \%$ diz que é uma vida satisfatória.

Outro aspeto abordado durante as entrevistas está na perceçáo dos pescadores quanto à diminuição das espécies capturadas nos últimos tempos, em que $78 \%$ dos entrevistados responderam que pescavam as mesmas espécies que atualmente, como, por exemplo, a cavala (Decapterus macarellus). Este peixe foi identificado como o peixe preferido pelos pescadores e consumidores. As estatísticas de pesca mostram oscilaçóes das capturas, com uma tendência crescente de 2004 a 2006, demonstrando com isso uma sobre-exploração da espécie (Tariche et al. 2012).

Embora sem informação científica suficiente, é provável que também outras espécies como 
o chicharro (Selar crumenophthalmus) e a cavala branca (Decapterus punstatus) estejam sob as mesmas condições de exploração intensiva, ocasionando a sua diminuição.

Segundo os pescadores, atualmente pescam-se algumas espécies, entre as quais a bicuda (Sphyraena), a façola (Priacantídeos), o sargo (Sparidae), o espadim azul (blue marlin) (Istiophoridae) e o barbo (Galeoides decadactylus), que não se pescavam antigamente.

Quando questionados sobre o período de defeso da cavala preta (Decapturus macarellus), do grupo das lagostas costeiras (lagosta verde (Panulirus regius), lagosta castanha (Panulirus echinatus) e lagosta de pedra (Scyllarides latus), bem como do da lagosta rosa(Palinurus charlestoni)), a opiniáo dos pescadores é favorável: $44,4 \%$ dos inquiridos acha o período muito bom, $44,4 \%$ acha que é bom.

O período de defeso da cavala preta, da lagosta costeira e da lagosta rosa fazem parte das medidas de desenvolvimento e de gestão para diferentes pescarias e diferentes horizontes temporais, visando a sustentabilidade racional dos recursos haliêuticos e o desenvolvimento do sector das pescas do Plano de Gestão dos Recursos da Pescas 2004-2014, elaborado no quadro do Plano de Acçáo Nacional para o Ambiente (ver Almeida et al., 2004).

Entre as principais medidas do plano constam as relativas às zonas reservadas, à proibição de práticas nocivas de pesca, ao estabelecimento do tamanho mínimo de espécies capturáveis e à fixação de períodos de defeso de espécies ameaçadas.

Em 2008, foi aprovado um conjunto de períodos de defeso para as lagostas de profundidade (01 de Julho a 30 de Novembro), para as lagostas costeiras (01 de Maio a 31 de Outubro) e para a cavala preta (01 de Agosto a 30 de Setembro). Foram ainda estabelecidos tamanhos mínimos de captura para a dobrada $(17 \mathrm{~cm}$ de comprimento medidos da ponta do rosto à barbatana caudal), lagosta rosa $(11 \mathrm{~cm}$ de carapaça), lagostas costeiras (9 $\mathrm{cm}$ de carapaça) e cavala preta $(18 \mathrm{~cm}$ de comprimento medidos da ponta do rosto à barbatana caudal).

Questionados sobre a necessidade de se adotarem períodos de defeso para outras espécies, além da cavala e da lagosta, as opinióes divergem, uma vez que, $48 \%$ dos inquiridos acha que o defeso deveria abranger outras espécies, entre as quais, o chícharo (Selar crumenophthalmus), a garoupa (Cephalopholis taeniops), o atum (Thunnus sp.) e o espadarte (Istiophoridae $s p$.). Já $44 \%$ respondem que não há necessidade de aplicar tais leis e $8 \%$ não tem opiniáo formada sobre o assunto.

Relativamente aos problemas que o sector da pesca artesanal enfrenta em Cabo Verde atualmente, 78\% dos pescadores da comunidade da Palmeira considera que este se centra nos poucos recursos para execução da sua atividade e os restantes $22 \%$ referem a má gestão dos recursos, sendo apontados também a falta de câmara frigorífica e a fraca intervençáo das autoridades no controlo da atividade piscatória. Por outro lado, apontam a poluiçáo, os acordos de pesca entre Cabo Verde e a Uniáo Europeia e os elementos externos (instabilidade do clima), como fatores que afetam a pesca no Porto da Palmeira.

A questão dos problemas ambientais aparece como um dos aspetos que mais precisa de ser trabalhado neste grupo, pois mais de metade dos 56\% dos inquiridos náo têm conhecimentos sobre o assunto. Alguns relatam as variáveis ambientais como fatores que interferem na pesca, como, por exemplo, o estado do mar (as marés) e o clima (condiçôes do vento, bruma seca e chuva), impeditivas à realizaçáo da atividade ou, até mesmo, colocando em risco a vida e a saúde do pescador. O clima e a poluição do mar também foram apontados como fatores comprometedores da sua qualidade de vida e do pescado por provocarem dificuldades financeiras, principalmente quando impedem a atividade ou quando geram prejuízos para os ecossistemas marinhos, principalmente desequilíbrio ecológico.

No desempenho da sua atividade profissional, 93\% dos inquiridos preocupa-se com a satisfação das geraçôes futuras e $7 \%$ diz que não. Usando a definição tradicionalmente adotada, o desenvolvimento sustentável é um desenvolvimento que deve responder às necessidades do presente sem pôr em risco as gerações vindouras.

A sustentabilidade ambiental da Terra está ligada diretamente a uma atitude de mudança de comportamento do ser humano no que diz respeito ao trato com a natureza. Nesse sentido, a dinâmica de exploração dos recursos naturais por parte das sociedades humanas requer cuidados no qual prevaleça a manutenção das espécies vivas da natureza. $82 \%$ dos inquiridos considera que estaria disposto a alterar alguns comportamentos, no desempenho da sua atividade, para que o recurso natural fosse preservado, enquanto que $11 \%$ refere que não e os restantes $7 \%$ não opinaram sobre tal atitude.

\section{DISCUSSÃO}

Os dados neste estudo indicam que a atividade da pesca é desenvolvida, na sua maioria, por homens com idade acima dos 35 anos, similar à encontrada nas outras ilhas. A média de idade dos pescadores a nível nacional é de 40 anos. No entanto, entre as ilhas, este valor varia entre os 37 e 43 anos. Em São Vicente recenseou-se o pescador mais velho de Cabo Verde (87) anos, e na ilha de Santiago o pescador mas novo com apenas 12 anos, enquanto as ilhas de Boavista e Maio são as que têm a média mais alta, 43 e 42 anos respetivamente (INDP, 2011).

Estes dados refletem o fato de os pescadores em atividade não serem jovens. Porém, pelo fato de a maioria deles pescar há mais de 20 anos, deduz-se que entraram jovens para a atividade de pesca. Portanto, a situação parece estar mudando atualmente, uma vez que poucos jovens estáo se iniciando na pesca, o que pode ser um indício do declínio da atividade. Por outro lado, uma vez que a escolaridade é obrigatória até ao sexto ano, isso pode indicar ainda que a escola impede que os jovens comecem a atividade táo cedo.

Constatou-se que o valor recebido na atividade pesqueira não é suficiente para o sustento da família, sendo que os pescadores, na sua maioria, e respetivas mulheres se dedicam a outras atividades remuneráveis, nomeadamente vendedeiras ou empregadas de limpeza para complementar o rendimento da pesca. Além disso, constatou-se ainda que a falta de infraestruturas para armazenamento e transporte do pescado obriga muitos pescadores a venderem, o quanto antes, o seu produto.

Os pescadores procedentes de outras localidades passaram a residir na ilha principalmente porque constituíram família 
ou porque procuravam novas oportunidades de trabalho geradas pelo turismo, pela pesca e pela sua opção profissional. Segundo Almeida et al. (2004), a nível do sector operam pescadores em dedicação exclusiva ou a tempo parcial. A pesca é uma alternativa durante os maus anos agrícolas.

$\mathrm{Na}$ atividade pesqueira cristaliza-se a divisão de género do trabalho. À semelhança de muitas outras comunidades piscatórias, espalhadas pelos cinco continentes, a maioria dos pescadores é constituída por homens que começaram a pescar com seus pais ou parentes, seguindo a tradição da família, aprendendo a pescar sozinho ou observando outros pescadores.

No tocante ao grau de escolaridade observado, um dos maiores problemas sociais que envolvem os pescadores artesanais do município poderá ser o alto índice de analfabetismo existente entre os integrantes desta profissão. Além do problema causado pela falta da educação escolar, a maior parte dos entrevistados possui apenas o ensino básico incompleto.

Apesar de muitos percalços na história de Cabo Verde, a instrução da população foi desde muito cedo reconhecida como uma das vias de ascensão económica e social e o analfabetismo, corretamente visto como um dos fatores fundamentais e determinantes da pobreza (INDP, 2001). Nesta ótica, o processo de instrução teve como estratégia abranger um cada vez maior número de pessoas nas idades pré-escolares e escolares, assim como, também, os adultos, através de programas específicos de alfabetização. Cabo Verde tem uma elevada cobertura escolar com uma taxa bruta de escolarização de $67 \%$ para mulheres e $82 \%$ para homens, em 2000 (INDP, 2001).

A maior parte das embarcações, 40,7\%, foi encomendada, enquanto $37 \%$ foi comprada e $3,7 \%$ não souberam responder qual a forma de aquisição. Esses dados não diferem dos dados apresentados pelo INDP, que constatou que a maioria das embarcações das ilhas de Cabo Verde era de propriedade dos pescadores.

Depois de 1992, alguns projetos foram implementados em Cabo Verde e executados pelo INDP, com diferentes fontes de financiamento, sendo uma parte com recursos internos e outra com recursos da cooperação bilateral ou multilateral, tentando ambos a melhoria das condiçóes de vida das comunidades piscatórias.

É predominante a arte de pesca com anzol e linha na localidade em estudo. Apesar de se utilizar as redes, espinhel e garrafas, a pesca com anzol e linha é um dos principais meios de subsistência em muitas comunidades piscatórias do país, confirmada por Almeida et al. (2004) como sendo a arte de pesca mais antiga praticada em Cabo Verde, e é comum em todas as comunidades piscatórias do arquipélago, representando $63 \%$ da captura artesanal e $93 \%$ do esforço da pesca artesanal.

De acordo com Medina (1995), as embarcações mais utilizadas na pesca artesanal são constituídas por pequenas embarcaçóes em madeira, de boca aberta e com reduzida autonomia no mar, nomeadamente para atuar em pesqueiros distantes. É uma atividade essencialmente costeira (INDP, 2010).

Com a pouca autonomia no mar conferida pelas embarcaçóes, $44 \%$ dos entrevistados afirmam que pescam no alto mar, 33\% disseram que concentram suas pescarias a quilómetros da costa e 19\% apenas atuam noutras ilhas.

Os pescadores dizem que náo capturam peixe sempre nos mesmos pesqueiros. $\mathrm{O}$ que os norteia na escolha do local adequado para a pesca é a própria experiência, alegando que se tivessem aparelhos como GPS e sondas, seria uma ajuda, sabendo de antemáo onde estavam os bancos de peixe.

Para Carvalho e Caramelo (1996), as espécies-alvo são os pequenos pelágicos como o charro-olho-largo (Decapterus macarellus), melão ou chicharro (Selar crumenophthalmus), podendo ainda aparecer nas capturas pequenos tunídeos. Corroborando tal teoria, os pescadores inquiridos afirmam que pescam outras espécies entre os quais, pequenos pelágicos como o charro-olho-largo, meláo ou chicharro, gaiado (Katsuwonus pelamis), cachorrinha ou judeu (Auxis thazard), atum (Thunnus albacares) e outros tunídeos (albacora e serra). Também predominam nas capturas, os peixes demersais (garoupa, moreias, salmonete, charuteiro, sargos e chicharro), usando a cavala, a cachorrinha, o chicharro, e o olho-largo para a captura das espécies acima identificadas, mas afirmam que a produção obtida por pescaria varia, de acordo com o tipo de pescaria e o tempo da faina. Quando questionados relativamente à perceção sobre se se pescava mais ou menos do que antigamente, $78 \%$ refere que se pescava mais, $11 \%$ diz que era menos, $7 \%$ igual e $4 \%$ não souberam responder.

De acordo com Plano de Gestão de Recursos de Pesca (ver Almeida et al., 2004), a pesca artesanal é uma atividade de grande tradição em todo o arquipélago, representando uma fonte importante de emprego e, para algumas ilhas, uma das bases produtivas fundamentais e eixo de desenvolvimento. A nível do sector, operam pescadores exclusivos e em tempo parcial, em que estes últimos provêm de outros ramos de atividade, os quais constituem, por vezes, uma alternativa durante os maus anos agrícolas.

É neste contexto que um dos objetivos últimos deste instrumento de pesquisa visa analisar a vida dos pescadores da localidade de Palmeira de modo a caracterizar a sua relação com a pesca enquanto fonte de emprego. A atividade piscatória é conhecida como uma vida dura, com rendimentos reduzidos. Assim, questionados sobre o modo de vida na pesca, $67 \%$ acha que é razoável enquanto 33\% diz que é uma vida satisfatória.

No tocante às dificuldades vividas durante os anos de trabalho, 78\% refere que pescam as mesmas espécies que antigamente contra $22 \%$ que acha que não. Cruzando os dados com Batista et al. (2009), em que os seus entrevistados dizem que a quantidade de peixes na comunidade tem diminuído de forma considerável e quanto ao tamanho dos peixes, os resultados indicam que $65 \%$ dos pescadores são da opinião que o tamanho das espécies tem diminuído.

No estudo de Batista et al. (2009) foi solicitada a opinião dos pescadores quanto ao desaparecimento de algumas espécies. Os resultados indicaram que $96 \%$ dos pescadores opinaram que algumas espécies desapareceram na comunidade. Do relato dos pescadores da Palmeira depreende-se que houve espécies que desapareceram enquanto se pescam algumas espécies que não abundavam anteriormente, entre os quais a bicuda, a façola (Heteropriacantus cruentatus), o sargo, o espadarte e o barbo (Galeoides decadactylus).

A ação do homem sobre o meio, a fim de saciar as suas 
necessidades, principalmente alimentares, é uma das grandes causas da modificação do ambiente. Rapidamente os recursos naturais foram desparecendo e por consequência, a qualidade de vida humana foi afetada.

\section{CONSIDERAÇÓES FINAIS}

A prática pesqueira artesanal é uma das mais antigas atividades humanas desenvolvidas em áreas litorais.

Como se pode observar pelos resultados deste estudo, a existência da pesca artesanal na comunidade estudada assume um papel crucial na vida desses pescadores.

Os resultados apontados neste estudo demonstraram a fragilidade da pesca tradicional, bem como dos pescadores, dada a baixa expectativa dos pais em relação à sua continuidade e à desmotivação dos mais jovens em aderir a uma profissão cujos resultados financeiros e sociais não se apresentam como muitos atrativos.

Ao longo do estudo foi possível ainda perceber que, apesar de os pescadores saírem táo cedo para o mar e da vida árdua que levam, das incertezas do dia-a-dia, da escassez de pescado, muitos, por náo terem conhecimento, ou porque acreditam que as causas dessa diminuição se devem apenas a outrem, não são capazes de melhorar os apetrechos, de ter alguma sensibilidade ambiental e acima de tudo de partilhar experiências, dificuldades e propor novos cenários.

Nesse sentido, e na posse dos dados analisados, podemos aferir que a relação existente entre os pescadores da comunidade da Palmeira, Ilha do Sal e o seu ambiente de trabalho se desenvolve baseado em saberes quotidianos, que lhes permitem ter um certo cuidado quanto ao uso e manejo dos recursos naturais marinhos. Desse modo a conceção deles acerca do cuidar do ambiente é permeada de saberes não-científicos e, por conta disso, muitos dizem "não ter qualquer conhecimento sobre os problemas ambientais".

Convém ressaltar que a visível preocupação quanto à conservação dos recursos pesqueiros, ao uso de materiais de pesca inadequados e à captura de espécies em período de defeso revela um conhecimento particular dos pescadores, levando-os a uma inquietaçáo sobre a forma errada de pescar, comprometendo, sem dúvida, o futuro daqueles que dependem dos recursos naturais marinhos e também a continuidade da atividade.

No geral, este estudo e a revisão bibliográfica preparatória do mesmo indicou que existem evidências de que a pesca em Cabo Verde e, principalmente, na Comunidade da Palmeira não tem ocorrido em moldes sustentáveis. Depois de identificadas as principais espécies piscatórias capturadas e de conhecer a dinâmica da vida dos pescadores, urge propor cenários de sustentabilidade para as pescas em Cabo Verde. É evidente que a implementação da redução da capacidade de pesca em Cabo Verde, quando o excesso da capacidade é um dos principais problemas que afligem os gestores de recursos pesqueiros, é uma política inaceitável, quando se verificam altas taxas de desemprego, tradição na atividade pesqueira e falta de alternativas sustentáveis nesta comunidade.

O governo de Cabo Verde tem poucas alternativas de estabelecer direitos de prioridade e redução de capacidade, devendo adotar medidas que visem a educaçáo, políticas de crédito e uso de novas tecnologias. A educação precisa ser o elemento emergente no processo de transformaçáo para uma organização social entre esses pescadores, pois a sua ausência na atual conjuntura política e económica fazse sentir na avaliação dos custos de produção e nos níveis de qualidade de vida dessas comunidades. A educaçáo e a organização dos pescadores, bem como a descentralização e a gestão participativa dos recursos pesqueiros são condiçóes fundamentais para a sustentabilidade da pesca.

A recomendação deste estudo é no sentido de que os órgãos governamentais estudem as comunidades piscatórias das nove ilhas habitadas, de modo a que ampliem as políticas voltadas para o incentivo à pesca artesanal, com financiamentos a juros baixos, que possibilitem a esse grupo um melhor equipamento para o armazenamento do pescado, a implementação de tecnologias de cultivo de peixes em cativeiro, e criação de um amplo programa de educação ambiental, que oriente as populaçóes quanto à preservação dos seus recursos naturais, com vista à sua sustentabilidade.

\section{BIBLIOGRAFIA}

Almeida, J.T.; Correia, M.A.; Pastor, O.T.; Barros, T.P. (2004) - Segundo Plano de Acção Nacional para o Ambiente. Documento Síntese. 34 p., Ministério do Ambiente, Agricultura e Pescas. Praia, Cabo Verde. Disponível em http://www.governo.cv/documents/PANAII-sintesefinal.pdf

Baptista, A.J.; Gominho, V.C.; Varela, A.S.; Tavares, V.H.; Lopes, H.G. (2009) - Percepção dos pescadores sobre a evoluçáo do estoque de recursos pesqueiros da ilha de Santiago. 47o. Congresso da SOBER, Sociedade Brasileira de Economia, Administração e Sociologia Rural, Brasília, DF, Brasil. Disponível em http://www.sober.org.br/ palestra/13/861.pdf

Carvalho, M.E.; Caramelo, A.M. (1996) - Avaliação do estado da pescaria da cavala preta e do chicharro. Investigação e Gestão haliêuticas de Cabo Verde, pp.144154, INDP - Instituto Nacional de Desenvolvimento das Pescas, Mindelo, São Vicente, Cabo Verde.

Deslandes, S.F. (2004) - La construcción del proyecto de investigación. In: Maria Cecília de Souza Minayo (Org.), Investigación social. Teoría, método y creatividad, $1^{a}$ ed., pp.25-39, Lugar Editorial, Buenos Aires, Argentina. ISBN: 9789508921710

Diegues, A.C. (1999) - A sócio-antropologia das comunidades de pescadores marítimos no Brasil: A pesca e os pescadores no Brasil, Etnográfica (2182-2891), III (2):361-37, Centro em Rede de Investigação em Antropologia, Lisboa / Braga, Portugal. Disponível em http://ceas.iscte.pt/etnografica/docs/vol_03/N2/Vol_iii_ N2_361-376.pdf

González, J.A.; Tariche, O. (eds.) (2009) - Um olhar sobre a biodiversidade marinha e bases para a sua gestão sustentável. Potenciais recursos pesqueiros de profundidade de Cabo Verde / Una mirada sobre la biodiversidad marina y bases para su gestión sostenible. Recursos pesqueros potenciales de profundidad de Cabo Verde. 176p., Fundación Universitaria de Las Palmas, Las Palmas de Gran Canaria, Espanha. ISBN: 978-8469241936. Disponível em http://issuu. com/oceanografica/docs/bioverde_por / http://issuu.com/ oceanografica/docs/bioverde_esp2 
Goodman, L.A. (1961) - Snowball Sampling. The Annals of Mathematical Statistics (ISSN: 0003-4851), 32(1):148170, Institute of Mathematical Statistics, Beachwood, OH, U.S.A. Article Stable URL: http://www.jstor.org/ stable/2237615

INDP (1999) - Boletim Estatistico. Dados sobre a Pesca Artesanal, Pesca Industrial, Conservas e Exportação. 89 p., INDP - Instituto Nacional de Desenvolvimento das Pescas, Mindelo, São Vicente, Cabo Verde. Não publicado.

INDP (2008) - Censo da Frota da pesca Artesanal 2005.75p., INDP - Instituto Nacional Desenvolvimento das Pescas, Divisão de Estatística, Mindelo, São Vicente, Cabo Verde. Não publicado.

INDP (2010) - Estatística das Pescas, 2008. Dados sobre a Pesca artesanal. Pesca Industrial. Conservas e Exportação. 75 p., INDP - Instituto Nacional Desenvolvimento das Pescas, Divisão de Estatística, Mindelo, São Vicente, Cabo Verde. Não publicado.

INDP (2011) - Estatística das Pescas 2009. Dados sobre a Pesca artesanal. Pesca Industrial. 75 p., INDP - Instituto Nacional Desenvolvimento das Pescas, Mindelo, São Vicente, Cabo Verde. Não publicado.

INDP (2012) - Relatório de principais resultados do censo geral da frota de pesca artesanal, industrial/semi-industrial de ano 2011. 16p., INDP - Instituto Nacional Desenvolvimento das Pescas, Divisão de Estatística, Mindelo, São Vicente, Cabo Verde. Não publicado.
Medina, A. (1995) - Le système statistique des pêches artisanales dans l'Archipel du Cap-Vert: Typologie des Ports et estimations des débarquements quotidiens. 180 p., Thèse de maîtrise, Université du Québec à Rimouski (UQAR), (Rimouski, QC, Canadá. Não publicado.

Merino, S. (2005) - O papel do INDP na Gestão Sustentável da Biodiversidade Marinha. VII Reunião Ordinária do Concelho Científico, pp.221-229, Mindelo, São Vicente, Cabo Verde. Não publicado.

Morin, E. (2011) - O método 3: conhecimento do conhecimento. $4^{\mathrm{a}}$ ed., 286 p., [Tradução para português do original francês, de 1986, por Juremir Machado da Silva] Editora Sulina, Porto Alegre, RS, Brasil. ISBN: 978-8520502204.

Thiollent, M.J.M. (1988) - Metodologia da pesquisa-ação. 4. ed., 108 p., Editora Cortez, São Paulo, SP, Brasil.

Tariche, O.; Correia, M.A.; Cruz, E.; Fonseca, A. (2012) $O$ defeso da cavala preta: Causas, impactos e alternativas. 18 p., INDP - Instituto Nacional Desenvolvimento das Pescas, Mindelo, Sáo Vicente, Cabo Verde. Disponível em http://portaldoconhecimento.gov.cv/ bitstream/10961/1525/1/A_Cavala\%C2\%B4s\%20 paper.pdf 